\title{
EGFR NP_005219.2:p.M766_A767insASV
}

National Cancer Institute

\section{Source}

National Cancer Institute. EGFR NP 005219.2:p.M766 A767insASV. NCI Thesaurus. Code C138903.

An insertion of the amino acid sequence alanine-serine-valine between the methionine at position 766 and the alanine at position 767 of the epidermal growth factor receptor protein. 